\title{
La complejidad de la investigación en liderazgo educativo, acercamientos metodológicos contemporáneos
}

The complexity of research in Educational Leadership, contemporary methodological approaches

\author{
Volumen 19, Número 1 \\ Enero-Abril \\ pp. 1-19
}

Este número se publica el 1 de enero de 2019

DOI: 10.15517/aie.v19i1.35239

Miguel Angel Díaz Delgado

Revista indizada en REDALYC, $\underline{\text { SCIELO }}$

Revista distribuida en las bases de datos:

LATINDEX, DOAJ, REDIB, IRESIE, CLASE, DIALNET, SHERPA/ROMEO, QUALIS-CAPES, MIAR

Revista registrada en los directorios:

ULRICH'S, REDIE, RINACE, OEI, MAESTROTECA, PREAL, CLACSO 


\title{
La complejidad de la investigación en liderazgo educativo, acercamientos metodológicos contemporáneos
}

The complexity of research in Educational Leadership, contemporary methodological approaches

\section{Miguel Angel Díaz Delgado ${ }^{1}$}

\begin{abstract}
Resumen: El presente ensayo entabla un debate sobre la investigación contemporánea en liderazgo educativo, propone ésta área de investigación como alternativa para la comprensión de las dinámicas organizacionales en el campo de la educación. El objetivo del documento es demostrar la complejidad de las teorías del liderazgo educativo a través de rastrear sus orígenes y exponer sus debates actuales. Se propone un agrupamiento desde las orientaciones conceptuales en operacional, analítica y dialógica, además de explicar los enfoques investigativos entitativo, relacional y sincrético. Se concluye que en las teorías del liderazgo educativo pueden construirse diseños investigativos complejos, debido a las variadas perspectivas que dan evidencia de dicotomía conceptual y entrelazamiento teórico-metodológico y, sobre todo, una indisoluble relación entre la teoría y la práctica. Esta discusión puede aportar a reconocer las propiedades de las teorías en cuestión y a reanimar el debate sobre sus límites en la construcción del conocimiento.
\end{abstract}

Palabras clave: metodología, liderazgo educativo, investigación educativa

\begin{abstract}
This academic essay develops a debate on contemporary research in Educational Leadership, stressing the complexity of its study and locating this line as an alternative for understanding organization dynamics in the Educational field. It is proposed a categorization of theoretical orientations -operational, analytical and dialogical- that represents a contemporary approach raised on the entitative, relational and syncretic focuses; these classifications are nowadays shaping the debate in this line of research. It is concluded that complex research designs can be constructed from the theories of Educational Leadership, due the varied perspectives that give evidence of conceptual dichotomy and theoretical-methodological intertwining but, above all, its indissoluble relationship between theory and practice. This discussion can contribute to recognize the properties of the theories in question and to reanimate the debate about their limits in the construction of knowledge.
\end{abstract}

Keywords: methodology, educational leadership, education research

\footnotetext{
1 Investigador de la Universidad Nacional Autónoma de México, Instituto de Investigaciones sobre la Univesidad y la Educación, México.
}

Dirección electrónica: interleader.diaz@gmail.com

Ensayo recibido: 28 de junio, 2018

Enviado a corrección: 24 de setiembre, 2018

Aprobado: 29 de octubre, 2018 


\section{Introducción}

Las políticas educativas impulsadas en varios sistemas educativos latinoamericanos se basan en reformas diseñadas por la tecnocracia (Gorostiaga y Tello, 2011; Guzmán, 2005; Vázquez, 2018). Dos ejemplos a destacar por su continuidad y sostenimiento en proyectos nacionales apoyados en las orientaciones del Banco Mundial (BM) y de la Organización para la Cooperación y el Desarrollo Económico (OCDE) son el caso de Chile y México. Estas políticas reducen el liderazgo educativo a esquemas de gestión burocrática y gerencial (Cruz, 2013), pues están regidas por conceptos ambiguos sobre la "eficiencia, eficacia, productividad, evaluación, certificación y acreditación" (p. 62).

Casanova (2016, p. 31) observa que específicamente en México "las políticas gubernamentales mantuvieron un esquema autoritario" que alcanzó al sistema público educativo de nivel obligatorio, donde se apostó por reformas reguladoras del profesorado. En estas políticas los "líderes escolares" son reducidos a figuras administrativas o de autoridad normativa y son empleados en la ejecución y vigilancia de las propias reformas, contrario al discurso de las mismas, donde el liderazgo se considera eje de transformación del sistema y un elemento articulador de la comunidad educativa.

A partir de 2013, la reforma educativa en el nivel primario observa al liderazgo bajo una serie de indicadores en los que priman las prácticas de "regulación social por medio de instaurar otras formas de trabajo y nuevas disposiciones" (Cruz, 2013, p. 73). Este modelo de gestión es gerencial y orienta el discurso de los procesos institucionales hacia "los líderes", quienes tienen la responsabilidad de los logros institucionales. Discursivamente se eleva a los líderes a un estatus de pieza clave para implementar la reforma educativa (Guzmán, 2014) y se les concibe como subsidiarios de la responsabilidad del Estado, en cuanto a brindar una educación de calidad.

En la reforma educativa 2013 de México "líder es lo mismo que tecnócrata" (Botero, 2018, p. 134), las nociones de liderazgo educativo propuestas carecen de profundidad, poco se cuestiona la validez de las teorías aplicadas y, en torno a una monocromía conceptual se impulsan técnicas que reducen el liderazgo a la implementación de estrategias para ganar adeptos, convencer a terceros e incrementar el carisma personal o profesional mediante el convencimiento del profesorado gracias al logro de metas, generalmente establecidas por entidades externas. 
Debido a la representatividad que ha ganado la visión tecnócrata del liderazgo, ciertos sectores académicos descartan casi automáticamente sus propuestas teóricas. Las razones centrales de la crítica académica se presentan porque [1] se perciben las teorías de liderazgo como una tendencia ajena a las realidades latinoamericanas, [2] se les exhibe como un asunto de moda (Lorenzo, 2005; Pariente, 2009), [3] se les considera una etiqueta evolutiva de las teorías administrativas (Eaccott, 2015), y [4] se les imputa simplismo metodológico. En contraparte, lo que se propone en el presente documento es que las teorías de liderazgo educativo tienen un potencial de complejidad, siempre y cuando se reconozcan sus orientaciones conceptuales y sus enfoques metodológicos, que escapan de la monocromía con la que las reformas tecnócratas instrumentan el liderazgo educativo.

El objetivo es demostrar la complejidad de las teorías del liderazgo educativo, a través de rastrear sus orígenes y exponer sus debates actuales, a partir de esta discusión se propone al liderazgo educativo como una línea de estudio consistente, tanto para la comprensión de las relaciones de poder, como para la toma de decisiones y el análisis de los procesos de agencia que dinamizan y tensan a las organizaciones educativas.

Es preciso en esta discusión impugnar las interpretaciones monocromas que exhiben al liderazgo educativo como un área predominantemente técnica, por lo que se expresa una crítica a las aplicaciones que carecen de revisiones serias en sus enfoques metodológicos. En última instancia, esta discusión de corte reflexivo puede aportar al reconocimiento de los componentes teórico-metodológicos de una investigación en el área y reanimar el debate sobre el conocimiento limítrofe del liderazgo educativo.

\section{Liderazgo educativo, de la monocromía a la complejidad}

Ciertamente, las teorías de liderazgo educativo se originaron en esferas académicas angloparlantes (Bolívar, López y Murillo, 2013) y no así en el ámbito latinoamericano o hispanohablante siquiera. Estas teorías provienen principalmente de países adheridos a la Commonwealth, que se ha desarrollado con mayor énfasis desde la posguerra.

Al igual que otras perspectivas teóricas, el liderazgo educativo se ha diseminado a partir de procesos de globalización del conocimiento, la relación entre redes investigativas de la Commonwealth y España en el tema fue impulsada por la corriente de los "movimientos para la mejora" (Bolívar et al., 2013; Hargreaves y Fink, 2008) que introdujeron, en los años noventa, estas teorías al ámbito académico hispanohablante. Por otra parte, el contacto 
entre las perspectivas norteamericanas "para la eficiencia" del liderazgo ha tenido también eco en diferentes países de Latinoamérica, sobre todo en México, donde varios de sus conceptos han sido adoptados y desarrollados desde la investigación y la práctica.

Hoy en día, las teorías de liderazgo tienen una mayor aceptación en la región y existe producción original desde universidades de Chile, Argentina, Colombia, México y Perú, entre otros países, que han generado diseños plenamente situados. Sólo por citar un ejemplo, en la construcción del estado del arte de una investigación sobre la formación de directores, desarrollada en la Universidad Nacional Autónoma de México (UNAM) se emprendió una búsqueda de artículos académicos, publicados entre 2012 y 2018, que dan cuenta de investigaciones relativas a las teorías de liderazgo educativo desarrolladas en contextos latinoamericanos. Las categorías de búsqueda fueron "liderazgo educativo" y "dirección escolar"; se cuidó que la segunda categoría fuera exclusivamente tratada desde la perspectiva de las teorías en cuestión, y no desde la gestión, la administración u otras. Se encontraron investigaciones sobre liderazgo educativo diversamente contextualizadas; dos estudios en Argentina, uno en Bolivia, trece en Chile, tres en Colombia, uno en Costa Rica, uno en Cuba, tres en Ecuador, cinco en México, tres en Perú y seis en Venezuela, además de cinco investigaciones mixtas o comparativas. Todo esto da un total de cuarenta y seis artículos publicados en el lapso que se menciona.

Estos resultados dan razón del crecimiento que está teniendo la investigación en liderazgo educativo en contextos latinoamericanos, pero también muestran la validez que tienen estas teorías para observar objetos de estudio derivados de contextos en la región. En países hispanohablantes los estudios sobre liderazgo educativo despuntaron desde hace veinte años, cuando se adhirió a una tendencia global que algunos teóricos sitúan ya en su quinta etapa de desarrollo (Burgess y Newton, 2015).

Según Cheong (2011) el liderazgo educativo se encuentra ante su tercera oleada y, asume que su origen se halla en la ruptura entre las teorías psicológicas humanistas y la administración estructuralista hacia los años cuarenta del Siglo XX. La discusión original se centró en torno a qué capacidades debían desarrollar los administradores para impulsar las organizaciones educativas, una de ellas era la de liderazgo. Así, las facultades en educación, sobre todo en países de la Commonwealth se preocuparon por dotar al personal administrativo educativo de capacidades como líderes institucionales, por lo que se abrieron colegios universitarios en Administración Educativa y Liderazgo, con interés en observar la 
relación entre ambos factores y se generó, además de una escalada en la formación, un "boom" en la investigación.

La segunda oleada se dio a partir del "movimiento teórico" encabezado por Thomas B. Greenfield a mediados de los años setenta. El teórico canadiense criticó la administración y el liderazgo educativo por estar excesivamente teorizados y centrados en el interés académico, desligados de contextos de práctica e inaccesibles debido a su sofisticación. Esto diversificó los sobre liderazgo educativo en esferas micropolíticas, como la escuela y la comunidad escolar, contradiciendo a la corriente tradicional que se enfocaba en las políticas educativas a escala sistémica.

En la década de los ochenta, al "movimiento teórico del liderazgo educativo" le hicieron eco los "movimientos de la escuela eficaz". Bajo este paradigma, Reino Unido, Estados Unidos (EEUU) y Australia, lo mismo que otros países y entidades europeas y asiáticas (Townsend y Macbeath, 2011) impulsaron métodos y teorías revisionistas para asegurar que los liderazgos del sistema educativo dieran soporte a las reformas de la época, emprendidas bajo la influencia de los nacientes organismos económicos globales, pero dirigidas a comunidades educativas específicas.

A partir de finales de los noventa y hasta la fecha, la tercera oleada de estudios globales sobre liderazgo educativo está en marcha, gracias a la intervención creciente de organismos económicos en las dinámicas de los sistemas educativos (Navarro-Corona, 2016; Pont y colegas, 2006), el desarrollo de colegios como el National College of School Leadership, en Inglaterra, y la creación de redes internacionales en liderazgo educativo a nivel global, además de la inclusión de universidades iberoamericanas.

Esta generación de estudios responde a una sociedad global "de aprendizaje, a lo largo de la vida y de múltiple desarrollo, en un ambiente de cambios rápidos e impacto desde la internacionalización de los avances tecnológicos" (Cheong, 2011, p. 261), y se caracteriza por la pluralidad y multiplicidad de entendimientos sobre el liderazgo educativo, sus dimensiones y metodologías.

Las aproximaciones académicas interesadas en estas teorías debaten entre propuestas integradoras y disruptivas, reconfigurando sus conceptos originales. Algunas tendencias pueden ser identificadas — tal como se desarrolla en los posteriores apartadospor su orientación conceptual y por sus diseños metodológicos. Sin embargo, desde la investigación en liderazgo educativo, no se sigue un patrón dictado para desarrollar 
investigación o para el seguimiento acrítico de determinadas propuestas teóricas. Una moda implica el seguimiento de patrones sin cuestionar, en contraparte esta proliferación de estudios no se entiende como tal. Más que una moda, el liderazgo educativo está atravesando por una etapa de expansión y resignificación que se enfrenta, como otras perspectivas teóricas, a los efectos inadvertidos de la globalidad, donde al mismo tiempo de propagar su difusión, muestra limitada su profundidad. Es preciso reposicionar el debate sobre las perspectivas contemporáneas sobre liderazgo educativo.

Respecto a la crítica del liderazgo educativo como una evolución categórica de la administración, Thomas B. Greenfield desplegó en sus estudios varias pautas para su diferenciación que marcan un distanciamiento con la administración estructuralista clásica, llevada del sector industrial y empresarial a la educación. En su obra, Greenfield propone la relación entre la administración y el liderazgo educativo como un elemento complementario, mas no idéntico (1975; Greenfield y Ribbins, 1993). Hoy se comprende, gracias al desarrollo que propició el "movimiento teórico" que la administración se centra en los procesos institucionales y el liderazgo, en los procesos de agencia de los sujetos; según Pariente (2009) los líderes se ocupan de la visión y la dirección de los cambios, mientras los administradores se encargan de monitorear los avances.

El límite entre la administración y el liderazgo se dibuja en la insuficiencia de la administración para crear sinergias y emplear el poder de manera no coercitiva ni autoritaria en las organizaciones educativas. En otras palabras, la administración puede delimitar los procesos a seguir dentro de una organización educativa, pero el liderazgo es el "motor de esa construcción histórica, social y cultural que llamamos centro educativo y organización en sentido más general" (Lorenzo, 2005, p. 368), desde el liderazgo se puede contribuir a configurar comunidades educativas, mientras desde la práctica administrativa se observan las reglas y procedimientos institucionales para lograr las metas.

Finalmente, en cuanto a la crítica sobre el simplismo metodológico y conceptual, más que señalar el conjunto general de teorías, se infiere que esta crítica apunta hacia una sola tendencia: la orientación del liderazgo hacia la eficiencia, adoptada por las reformas tecnócratas. El liderazgo educativo en su conjunto no se reduce a propuestas teóricas monocromas desdobladas por la acción normativa, moral o ejecutiva para administradores o directores, eufemísticamente nombrados líderes, tal como sí lo enfoca la tendencia en 
cuestión. La investigación en liderazgo educativo muestra diversidad y dicotomía conceptual, además de pluralidad en sus enfoques investigativos.

Para acceder a estas teorías de manera esquemática se han llevado a cabo diversas revisiones y clasificaciones. Burgess y Newton (2015) reconocen el área basados en su correlación disciplinar; Botero (2018) igualmente lo analiza en función de las disciplinas hacia las que se orienta; Bolívar y colegas (2013) proponen un acercamiento donde cobra relevancia la dirección de la acción investigativa del liderazgo; Pariente (2009) aporta una clasificación por teorías, comportamientos, escuelas y modelos; del Valle (2015) y NavarroCorona (2016) lo observan desde su enfoque de práctica; Rojas y Gaspar (2006) lo clasifican por dimensiones. Otros varios autores han aportado clasificaciones según estilos (Ewin, Lippitt y White, 1939; Maureira, Garay y López, 2016; Semprún y Fuenmayor-Romero, 2007; Sergiovanni y Corbally 1984), modelos y tipologías (Lorenzo, 2005; Marchesi, 2000), o con base en conceptos metafóricos (Lorenzo, 2005).

El liderazgo educativo es una línea de investigación y de práctica enfocada a estudiar la agencia, la toma de decisión y las dinámicas de acceso al poder —como posibilidad y como elemento coercitivo- en el marco de las organizaciones educativas. En la investigación sobre liderazgo educativo se pueden generar esquemas analíticos o dirigidos a la práctica de tomadores de decisión, directivos e, incluso, profesores y estudiantes. Descartar las teorías de liderazgo por su origen, o concluir que el repunte en el número de investigaciones es razón para no considerarlas sustentables, anula un bagaje teórico y metodológico valioso para la comprensión y la transformación de las organizaciones educativas. La mirada monocroma descrita en el apartado anterior no se aleja de esta posición.

No obstante, se ha encontrado polisemia y dinamismo analítico en las orientaciones conceptuales sobre liderazgo, mientras que, en sus enfoques metodológicos, se halla la posibilidad de realizar diseños comprehensivos para la investigación. Demostrar que la línea de investigación en liderazgo educativo tiene el potencial de generar aproximaciones metodológicas complejas vuelve más necesario el análisis de sus orientaciones conceptuales y de sus enfoques, que acercarse a la polisemia conceptual generada por estas teorías o permanecer en la monocromía pragmática impulsada en algunas reformas. Es por ello que a continuación se discutirán tres orientaciones conceptuales básicas y tres enfoques 
metodológicos presentes en la investigación contemporánea que dan fe de dicha complejidad.

\section{Orientaciones conceptuales en el liderazgo educativo}

El liderazgo educativo es una línea de investigación plenamente vinculada a la práctica. Las propuestas investigativas están orientadas a generar conocimiento y marcos de acción para la toma de decisiones, el ejercicio y la distribución de los poderes, además de la comprensión de la agencia de grupos y personas en las organizaciones educativas. Analizar la orientación conceptual implica reconocer hacia dónde se dispone la acción investigativa, cuáles son las variables o categorías centrales y de qué conceptos se parte en la investigación. Entre la diversidad de conceptos contemporáneos en torno al liderazgo educativo pueden distinguirse, por lo menos, tres grandes orientaciones: una operacional, plenamente dedicada a generar esquemas de acción; una analítica, encaminada a la comprensión de las dinámicas de liderazgo en las organizaciones educativas; y una dialógica, comprendida como la intersección entre ambas.

En la orientación operacional el liderazgo se concibe como un proceso de influencia para la dinamización de las prácticas educativas (Bolívar et al., 2013; Davies, 2005; Hargreaves y Fink 2008; Townsead y MacBeath, 2011), donde los líderes escolares principalmente los directores o coordinadores con cargos administrativos - impulsan iniciativas a través de la administración y de la gestión, encaminadas al logro de objetivos específicos de la organización. La investigación con orientación operacional observa "los liderazgos en las organizaciones escolares y su influencia en los agentes de las instituciones" (Rodríguez y Gairín, 2017, p. 8). Se puede definir el liderazgo, operacionalmente, como "la función de dinamización de un grupo o de una organización para generar su propio crecimiento en función de una misión" (Lorenzo, 2005).

Los productos investigativos desde la orientación operacional son diversos, pero destaca la generación marcos de acción que permiten a los agentes reconocer qué se espera de su actuación en contextos educativos. Esta orientación generalmente se relaciona con estudios sobre eficacia educativa, donde importa reconocer cuál es el alcance o impacto de la labor de los directores en el logro de las metas tanto escolares como sistémicas.

Una de las críticas hacia esta orientación radica en en el riesgo de constituir propuestas monocromas de liderazgo, sobre todo porque en sus análisis se ata a los líderes 
a los objetivos institucionales, donde un líder es considerado como tal en relación a los resultados que logra en una lógica de regulación. Un ejemplo es la regulación reformista de nivel educativo básico en México, donde el liderazgo de los directores está siendo evaluado con base en perfiles y parámetros homogéneos, y no bajo la revisión acompañada de su desempeño en los contextos escolares. Los diseños con orientación operacional, deben estar advertidos de las consecuencias de generalizar los resultados y de proponer recetas sobre el liderazgo para la práctica, sin contextualización alguna.

Las orientaciones analíticas, por su parte, están centradas en estudiar las disposiciones y acciones que dotan de un sentido a la organización escolar, en estudiar los liderazgos formales y latentes en las organizaciones o las comunidades educativas, y las relaciones que se entablan en la organización para generar liderazgos. Desde la orientación conceptual analítica se intenta descubrir cómo influye "la organización escolar [...] en el comportamiento de sus miembros" (Robinson, Hohepa y Lloyd, 2009, p. 21) y, en sentido inverso, cómo los líderes también influyen en la configuración organizativa.

En la orientacion analítica se precisa estudiar las relaciones que predeterminan 0 generan liderazgos, además de las dinámicas para la toma de decisión y los intersticios de agencia en la organización educativa. Sin obstar que el acercamiento sea a la práctica o teórico, "el poder se convierte en la variable central para entender los resultados de la interacción social" (Guzzini, 2015, p. 98) específica del ámbito educativo. Este análisis es dicotómico, puesto que dicho poder puede radicar en el convencimiento de los otros "para lograr algo" o, contrariamente, en la influencia contextual u organizacional sobre las maneras en que se lidera una organización. A pesar de que el liderazgo descansa en "una estructura cuya razón y legitimidad [...] [es] reconocida tanto por los que mandan como por los que obedecen y donde cada uno tiene un lugar jerárquicamente definido" (Arendt, 1976, p. 93).

El conflicto es otro elemento que predetermina o reorienta los esquemas de acción y las condicionantes contextuales en las que estos liderazgos operan. Esto es bien comprendido por los diseños con orientación analítica, que reconocen que "el liderazgo no es en modo alguno un fenómeno o una práctica individual, sino constitutivamente social" (Bolívar et al., 2013, p. 33), y que los parámetros para observar el liderazgo son contextuales. Por ello, sus constructos renuncian a la simple generación de esquemas de acción y se desmarcan del llano análisis de las propiedades personológicas de los líderes 
educativos, cambiándolos por constructos teóricos más elaborados: propuestas teóricamente sustentadas, análisis riguroso de la práctica, meta-investigaciones, entre otros.

Una de las críticas a los productos investigativos con orientación analítica radica en la densidad conceptual que de ellos puede provenir. Los aportes desde esta orientación pueden encontrar dificultades en la instrumentación administrativa, política y directiva, que, por su parte, requieren de inmediatez en la toma de decisiones. Otra de las críticas radica en las bajas posibilidades de generalización de sus constructos, puesto que el análisis debe ser centrado en contextos específicos para encontrar mayor profundidad.

La tercera orientación conceptual es la dialógica, que tiende un puente de diálogo entre la orientación operacional y la analítica. Su lógica puede comprenderse bajo los aportes habermasianos de la acción comunicativa, "situada en lo que efectivamente ocurre en el mundo de la vida, con todas sus distorsiones, juegos de intereses y manipulaciones del poder" (Silva, 2015, p. 175). La orientación dialógica reconoce necesario generar esquemas operativos para las organizaciones educativas sin renunciar al análisis profundo de los conceptos y las dinámicas del liderazgo educativo. Esta orientación exhibe la dicotomía entre el concepto de liderazgo, como la influencia de unos hacia los otros - presente en la orientación operacional-, y la comprensión de los contextos, como elementos predeterminantes de las relaciones en las organizaciones educativas, propia de la orientación analítica.

La lógica investigativa de la orientación dialógica se dirige al diálogo con la realidad, "dejando que ésta misma despliegue su expresividad y su modo específico de ser" (AbellánGarcía, p. 113). Algunos conceptos dialógicos del liderazgo -entre ellos las orientaciones del liderazgo democrático para la justicia social y distributiva- establecen críticas abiertas a las estructuras educativas que se reúsan a flexibilizar la autoridad (liderazgo formal, directivo, ejecutivo o gerencial), que condicionan la distribución de poder al acatamiento de normas inflexibles, y que basan su ejercicio en la toma de decisiones no necesariamente racionada ni justa.

Al igual que en la orientación analítica, se entiende que la interacción con los contextos predetermina la forma en que los sujetos se relacionan con las instituciones y los fines educativos. No obstante, los constructos bajo la orientación dialógica, principalmente en los conceptos democráticos y distributivos del liderazgo para la justicia social, se precisa que 
esta interacción contexto-agentes no sólo sea analizada para seguir predeterminándolos, sino para generar una conciencia transformadora.

El análisis de la categoría de poder es dicotómico, puesto que el mismo puede ser tanto subyacente como predeterminante del liderazgo; sin embargo, en esta orientación, más que el poder, la agencia es la categoría central de análisis. La orientación dialógica se enfoca en los mecanismos institucionales simbólicos para convencer-se y auto-operar (Sloterdijk, 2014) en un contexto de interacciones, donde el poder se supedita a la agencia, una relación que implica "la probabilidad de realizar la propia voluntad, en una relación social" (Silva, 2015, p. 180). El liderazgo es siempre una posibilidad que "deriva de la acción, que es una cosa imprevisible", por lo que ninguna finalidad podría ser considerada "como medida para evaluar el poder originado, pues eso significaría imponer fines a la acción, lo que quitaría su carácter" (Abreu, 2004, p. 39).

De otra parte, el análisis del conflicto es adherido a una "lógica que procura la integración por vía de profundidad (lo que permite resolver la tensión por elevación, en las realidades tensionadas no se pierden, sino que se promocionan)" (Abellán-García, 2015 p. 114); es decir, el conflicto más que ser superado, es comprendido como parte de la construcción social y organizacional. La labor de quienes ostentan cargos de liderazgo es, por añadidura, una labor de medicación y facilitación organizacional, no una guía, como en la orientación operacional.

La orientación dialógica propone tanto esquemas —no generalizables - para el desarrollo del liderazgo, como desarrolla constructos teóricos que develen las relaciones que lo predeterminan. Sin embargo, para evitar que sus propuestas de liderazgo se reduzcan a simples fórmulas con un poco de cada orientación, es preciso generar diseños metodológicos integrados, con congruencia interna a través de la reflexividad, que, aporten propuestas, explicaciones y modelos de intervención más ajustables a la comprensión de la realidad de contextos específicos (Gairín, 1999 y 2010). Es decir, se requiere que sus constructos reconozcan también aquellas cuestiones que predeterminan a la investigación sobre liderazgo.

Así, la investigación en liderazgo educativo se puede comprender bajo una pluralidad indeterminada de conceptos. Las orientaciones conceptuales mencionadas no pretenden ser una clasificación más de los estudios de liderazgo, sino una agrupación de la amplia gama de clasificaciones que se han desarrollado. Tampoco se pretende un agrupamiento 
irrefutable, sino hacer notar la dirección hacia donde se orienta la acción investigativa, según sus conceptos, observables y productos.

La diferencia en cada orientación radica centralmente en que la operacional despliega marcos de acción para el liderazgo, la analítica constructos analíticos de la acción del liderazgo y, la dialógica, establece un diálogo abierto en sus propuestas, atendiendo a la necesidad de generar tanto esquemas analíticos como operativos. Cada orientación exhibe una permanente dicotomía y contradicción entre el concepto de liderazgo, entendido como "proveer dirección y ejercer influencia" (Bolívar, 2010, p. 22), y la medicación entre condiciones institucionales y contextuales para la toma de decisiones y para la estimulación de la agencia de los sujetos.

\section{Enfoques contemporáneos en la investigación sobre liderazgo educativo}

En la metodología de la investigación sobre liderazgo el enfoque responde a las preguntas acerca del diseño de investigación, entre ellas, cómo se diseña, qué lógica sigue, a quién se investiga y bajo qué condiciones. Siguiendo esta perspectiva, Scott Eacott (2014) ha desarrollado un análisis de los estudios de liderazgo "posmodernos" o contemporáneos: el entitativo y el relacional. Además, aquí se propone una tercera opción: el enfoque sincrético, como una fusión de ambos.

El enfoque entitativo, con cimientos en el pospositivismo y el funcionalismo organizacional, reconoce panorámica y esquemáticamente las maneras en que el liderazgo se ejerce. Su intervención metodológica encapsula unidades de análisis, con el fin de observarlas y de reconocer sus propiedades. El acercamiento puede ser explicativo o descriptivo, pero siempre es funcional y estructural, ya que permite reconocer cuáles son las propiedades de un objeto de estudio, sus componentes y características, además de proporcionar datos sobre los efectos de una unidad de análisis sobre otra.

El enfoque relacional, por su parte, está vinculado con el construccionismo social y con las corrientes interpretativas y sociocríticas. Su objetivo es reconocer el liderazgo a través de la construcción de marcos de análisis multidimensional de las organizaciones educativas. El diseño de investigación extiende sus objetos de estudio hacia los límites de la institución, dirigidos por lo general a la sociedad, pero se encuentran a menudo otros estudios donde la frontera con la sociología es tenue. Aquí se reconoce que las unidades analíticas propuestas por el enfoque entitativo son una mera reducción, y que no se espera encontrarlas 
"encapsuladas" en la realidad social, o en tal caso educativa, como lo plantean los estudios entitativos.

Los diseños relacionales consideran faccioso que una unidad de análisis se encuentre aislada de otras unidades en la realidad, o que sus vínculos con las organizaciones educativas encuentre linealidad entre causa-efecto. Por ejemplo, para un estudio entitativo, un curso de formación de directores influiría de manera "determinante" en la forma en que desarrolla su liderazgo; para un diseño relacional, el diseño incluirá observables como su trayectoria profesional, las condiciones contextuales, los significantes sobre la dirección, entre otros que se entrelazan de manera compleja. De tal manera, la investigación entitativa encapsularía a cada unidad -programas formativos, liderazgo- para analizar sus componentes, mientras que la relacional los enlazaría, al hacer visibles las intersecciones entre cada observable.

Los diseños relacionales estudian la agencia, la determinación y la toma de decisiones entre sujetos, instituciones, sistemas y comunidades educativas (Eaccott, 2013 y 2015), en el entendido de que la revisión de esas prácticas se da en un continuo indeterminado de relaciones contextuales e intersubjetivas. Estos diseños también se avocan a la comprensión de unidades interrelacionadas y a las condiciones predeterminantes de las mismas, y estresan al objeto de estudio cuando lo problematizan, en un proceso de deconstrucciónconstrucción de los significantes de liderazgo. Sin embargo, una de las desventajas de estos diseños radica en la complejidad del análisis, además de que, si no se cuenta con procesos reflexivos en la investigación, se corre el riesgo de perderse en una infinidad de categorías teóricas y prácticas. Por ello, un estudio relacional, precisa de delimitaciones claras.

Una tercera vía es el enfoque sincrético de liderazgo, al cual se le considera una mezcla del enfoque relacional y del entitativo. Esta vía, más que seguir una orientación en particular, se rige por el pragmatismo metodológico, y su expresión en los diseños combina el análisis de entidades con el análisis de unidades interrelacionadas. El enfoque sincrético prioriza los diseños de investigación estratégicos, tomando en cuenta el contexto mismo de la acción del liderazgo. No obstante, una de las críticas a este enfoque es el alto compromiso funcional respecto de las perspectivas hegemónicas y la combinación antitética de diseños de investigación.

En resumen, la investigación contemporánea presenta tres grandes enfoques bajo los cuales se diseñan sus modelos —el entitativo, el relacional y el sincrético- que pueden ser 
analizados en el diseño teórico-metodológico de las investigaciones. Si una investigación desarrolla una metodología que encapsula unidades de análisis para reconocer cómo una influye a la otra, se habla de un diseño con enfoque entitativo; si su diseño vincula observables de manera interrelacionada, es una investigación relacional y, por último, si mezcla ambos tipos de diseño, se habla entonces de un enfoque sincrético. Cada tipo de diseño tiene alcances y limitaciones aquí enunciadas, quien haga investigación sobre liderazgo educativo puede reconocerlas y observar la construcción metodológica de las mismas.

\section{Conclusiones}

El presente texto ha explicado que las reformas educativas tecnócratas reducen las teorías de liderazgo educativo a eufemismos de las prácticas estructuralistas tardías de la administración, que suelen acercarse de manera monocroma y, por lo tanto, incompleta respecto de la comprensión de esta línea de investigación. Es cierto que uno de los intereses particulares de la investigación en liderazgo es la dirección de organizaciones educativas, pero los acercamientos monocromos pasan por alto que, en en este análisis "si consideramos liderazgo como la función que desempeñan determinadas personas -los líderes- entonces nos perderemos una buena parte del fenómeno" (Bolívar et. al., 2013, p. 35). Por eso se ha concluido que esta línea no se enfoca de manera exclusiva al análisis de características personológicas de "líderes" y que, incluso, su acercamiento merece una aproximación multifactorial y contextual.

El reduccionismo de las reformas tecnócratas ha provocado las críticas de la academia latinoamericana con sobrada razón hacia las teorías de liderazgo educativo. Queda claro que en el tratamiento de las reformas —en particular en la de México- se pasan por alto que el área de estudio comprende ya un conjunto de orientaciones y de enfoques, que se acercan de modo diferenciado a un compendio extenso de objetos de estudio. La investigación en liderazgo educativo emerge en contextos académicos de habla hispana hasta después de un desarrollo sostenido en contextos angloparlantes, pero hoy se le considera una opción para el análisis de las prácticas y de las condiciones que impulsan y tensan las dinámicas de las organizaciones educativas.

El análisis de estas páginas no atiende detalladamente el estado del arte en torno de las teorías de liderazgo educativo, ni tampoco articula una tendencia de las orientaciones o 
enfoques preferentes en los estudios hispanohablantes del área. No obstante, este análisis sí da evidencia de una pluralidad de tipificaciones propuestas en estas mismas teorías. La discusión sobre orientaciones y enfoques en liderazgo educativo caracteriza una línea de investigación potencialmente compleja, si se toma en cuenta la dicotomía de sus orientaciones conceptuales y el entrelazamiento entre la teoría y la metodología, presente en los enfoques investigativos.

A pesar de la relación estrecha entre la teoría y la práctica del liderazgo, no toda investigación se traduce necesariamente en un esquema de acción, los constructos investigativos pueden desarrollarse también como propuestas analíticas. Identificar la orientación de la investigación en liderazgo aporta a reconocer qué conceptos, variables, observables y productos de investigación pueden surgir de ella.

En cuanto al análisis de la metodología, desde las teorías de liderazgo, se han encontrado tres enfoques distintos: los entitativos, que encapsulan entidades de análisis; los relacionales, que las vinculan entre sí y con su estructura; además de los modelos sincréticos, que son una mixtura entre los dos enfoques anteriores. Reconocer el enfoque en el diseño metodológico permite establecer las correlaciones existentes en los objetos de estudio.

De tal modo, en este nicho de investigación prima la complejidad debido a la dicotomía y a la diversidad conceptual. La reflexión a partir de las orientaciones conceptuales y del enfoque metodológico procura la interrelación de los observables y ayuda a evidenciar la indisolubilidad entre teoría y práctica. Se precisa con estos planteamientos, que los diseños de investigación precisan de reconozcan cuál es su orientación conceptual y su enfoque metodológico, para aportar a los diseños investigativos de cierta congruencia teóricometodológica interna.

Debido a que la mayoría de las orientaciones conceptuales contemporáneas de liderazgo educativo toman en cuenta que "ni la red de interacciones ni la actividad organizativa se producen en el vacío, sino que están condicionadas [...] por un contexto social de normas, procedimientos, valores y expectativas” (Bolívar et. al., 2013, p. 36), se asume que la crítica sobre el simplismo en la investigación del área, más que dirigirse a las teorías sobre liderazgo educativo en su conjunto, se centra en en las propuestas monocromas que apuestan por la aplicación acrítica de dichas teorías. Esta es una 
tendencia, por cierto, privilegiada por las reformas tecnócratas, que han acaparado el liderazgo educativo como un concepto propio, en sistemas educativos de Latinoamérica.

Los diseños de investigación deben advertir la necesidad de la innovación y generar un debate permanente sobre la complejidad de los constructos, a fin de no terminar siendo propuestas de análisis que aten la investigación a nuevas formas de alineamiento institucional, o que propicien esquemas doctrinarios de liderazgo en la práctica Por ello es preciso salvar las propuestas teóricas de la monocromía conceptual, que se dedica a la generación de normas de conducta para los líderes. Por último, resulta ineludible identificar relaciones veladas en la realidad educativa y cómo estas se vinculan con las estructuras y los contextos donde se desarrolla el liderazgo.

\section{Referencias}

Abellán-García, Álvaro. (2015). De la dialéctica a la dialógica. Mar Oceana: Revista de humanismo español, (31), 97-125. Recuperado de http://ddfv.ufv.es/bitstream/handle/10641/970/dialectica\%20abellan.pdf?sequence=1

Abreu, Maria. (2004). Hannah Arend e os Limites do Novo. Rio de Janeiro, Brasil: Azougue.

Arendt, Hannah. (1976). The origins of totalitarianism. New York, US: Hacourt Brace Jonavovich.

Bolívar, Antonio, López Julián y Murillo, Javier. (2013). Liderazgo en las instituciones educativas. Una revisión de líneas de investigación. Fuentes (14), 15-60. Recuperado de

https://idus.us.es/xmlui/bitstream/handle/11441/33743/Liderazgo\%20en\%20las\%20insti tuciones\%20educativas.pdf? sequence $=1 \&$ isAllowed $=y$

Bolívar, Antonio. (2010). Liderazgo pedagógico: una dirección para el aprendizaje. OGE, (1) $15-20$, Recuperado https://www.essr.net/ jafundo/mestrado material itgikhnld/IV/Lideran\%C3\%A7as/Boliv ar LiderazgoparaelAprendizaje.pdf

Botero, María. (2018). Lo que llamamos liderazgo: consideraciones críticas de lo que ocurre en diversas organizaciones. Perspectivas Psicológicas, 3(4), 134-144. Recuperado de http://pepsic.bvsalud.org/pdf/pp/v3-4/v3-4a15.pdf

Burgess, David y Newton, Paul. (2015). Educational Administration and Leadership. Theoretical foundations. Rotterdam, Holland: Routledge.

Casanova, Hugo. (19 de julio, 2016). La política educativa y el fracaso de la tecnocracia. La Jornada. Recuperado de http://www.jornada.unam.mx/2016/07/19/opinion/016a2pol 
Cruz, Ofelia. (2013). Políticas para las escuelas Normales: Elementos para una discusión. En Patricia Ducoing (Coord.), La Escuela Normal. Una mirada desde el otro (pp.49-77). Ciudad de México: IISUE, UNAM.

Cheong, Yin. (2011). Hacia el tercer paradigma del liderazgo de la escuela. Revista de Investigación Educativa. 29(2), 253-275, Recuperado de http://revistas.um.es/rie/article/view/130811/121701

Davies, Brent. (2005). The essentials of school leadership. London, England: Paul Chapman Educational \& Corwin Press.

Del Valle, Ingrid. (2015). Liderazgo distributivo: una nueva visión del liderazgo educativo, en Innovación y cambio en las organizaciones educativas. En Aurelio Villa (Coord.), Congreso Internacional sobre dirección de centros educativos. Bilbao, España. Recuperado de https://dialnet.unirioja.es/servlet/articulo?codigo=2728766

Eacott, Scott. (2013). Research as a political practice: The fallacy of data speaking for themselves. In Eacott Scott and Richard Niesche (Eds.), Empirical leadership research: letting the data speak for themselves (pp. 215-229). New York, EUA: Untested Ideas Center.

Eacott, Scott. (2014). Educational Leadership Relationally: A Theory and Methodology for Educational Leadership, Management and Administration. Rotterdam, Holland: Springer.

Eacott, Scott. (2015). Educational Leadership Relationality: A Theory and Methodology for Educational Leadership, Management and Administration. Rotterdam, Holland: Sense Publishers.

Ewin, Kurt, Lippitt, Ronald y White, Ralph. (1939). Patterns of aggressive behaviour in experimentally created social climates. Journal of Social Psychology, (10), 301-320.

Gairín, Joaquín. (1999). La organización escolar: contexto y texto de actuación. Madrid, España: La Muralla.

Gairín, Joaquín. (2010). El liderazgo educativo. Los equipos directivos en centros de secundaria, elementos básicos del éxito escolar. Madrid, España: Ministerio de Educación, Servicio de Publicaciones.

Greenfield, Thomas y Ribbins, Peter. (1993). Greenfield on educational administration: towards a human science. London, UK: Routledge press.

Greenfield, Thomas. (1975). Theory about organizations: $A$ new perspective and its implications for schools in Administering education: international challenge. London, UK: Athlone press. 
Gorostiaga Jorge y Tello, César. (2011). Globalización y reforma educativa en América Latina: un análisis inter-textual. Revista Brasileira de Educação,16(47), 363-389. Recuperado de www.redalyc.org/articulo.oa?id=27519919006

Guzmán, Carolina. (2005). Reformas educativas en América Latina: un análisis crítico. Revista Iberoamericana de educación, 36(8), 1-13. Recuperado de https://rieoei.org/RIE/article/view/2779

Guzmán, Julieta. (11 de noviembre, 2014). Líderes escolares, pieza clave para implementar la reforma educativa, educación en México. [mensaje en un blog]. Recuperado de http://www.mexicanosprimero.org/index.php/educacion-en-mexico/nuestraopinion/item/lideres-escolares-pieza-clave-para-implementar-la-reforma-educativa

Guzzini, Stefano. (2015). El poder en Max Weber. Relaciones internacionales, (30), 97-115, Recuperado https://repositorio.uam.es/bitstream/handle/10486/677087/RI 30 6.pdf?sequence=1

Hargreaves, Andy y Fink, Dean. (2008). El liderazgo sostenible: Siete principios para el liderazgo de centros educativos. Madrid, España: Morata.

Lorenzo, Manuel. (2005). El liderazgo en las organizaciones educativas: revisión y perspectivas actuales. Revista española de pedagogía, 63(232), 367-388.

Marchesi, Álvaro. (2000). El fracaso escolar. Madrid, España: Fundación por la modernización de España.

Maureira, Óscar, Garay, Sergio y López, Pablo. (2016). Reconfigurando el sentido del liderazgo en organizaciones escolares contemporáneas: La perspectiva del liderazgo distribuido. Revista complutense de Educación, 27(2), 689-706. Recuperado de https://revistas.ucm.es/index.php/RCED/article/viewFile/47079/48402

Navarro-Corona, Claudia. (2016). Consideraciones teóricas sobre el concepto de liderazgo y su aplicación en la investigación educativa. Revista Educación, 40(1), 53-66. Recuperado de https://revistas.ucr.ac.cr/index.php/educacion/article/view/16148

Pariente, José Luis. (2009). Algunas reflexiones en torno al concepto del liderazgo, en Procesos de cambio y desarrollo organizacional. En Jessica Mendoza (Coord.), Proceso de cambio y desarrollo organizacional (pp. 117-147). Aguascalientes, México: UAT.

Pont, Beatriz, Nusche, Deborah y Hopkins, David. (2008). Improving School Leadership (Vol. 2, Case studies on system leadership). Paris, France: OECD.

Robinson, Viviane, Hohepa, Margie y Lloyd, Claire. (2009). School leadership and student outcomes: Identifying what works and why: Best evidence synthesis iteration (BES). Wellington, New Zeland: Ministry of Education. 
Rodríguez, Guillermo y Gairín, Joaquín. (2017). Influence of the practices of pedagogical leadership in the educational pedagogical practices: case in Chile of the Pedagogical Technical Units. International Journal of Educational Leadership and Management, 5(1), 6-29. Retrieved from http://hipatiapress.com/hpjournals/index.php/ijelm/article/view/2469

Rojas, Alfredo y Gaspar, Fernando. (2006). Bases del liderazgo en educación. Santiago, Chile: OREALC/UNESCO.

Semprúm-Perich, Richard y Fuenmayor-Romero, Johanna. (2007). Un genuino estilo de liderazgo educativo: ¿una realidad o una ficción institucional?, Laurus, 13(23), 350-380. Recuperado de http://www.redalyc.org/pdf/761/76102318.pdf

Sergiovanni, Thomas y Corbally, John. (1984). Leadership and Organizational Culture: New Perspectives on Administrative theory and practice. Chicago, US: University of Illinois press.

Silva, Adilson. (2015). Violencia y poder en el pensamiento político de Habermas y Hanah Arendt. Contemporánea. Revista de ética e filosofía política, 1(1), 1-21.

Sloterdijk, Peter. (2014). Esferas I. Madrid, España: Biblioteca de ensayo Siruela.

Townsend, Tony y Macbeath, John. (2011). International Handbook of Leadership and Learning. New York, US: Springer.

Vázquez, Gabriela. (2018). La calidad de la educación. Reformas educativas y control social en América Latina, Latinoamérica, revista de estudios latinoamericanos, (60), 93-124. Recuperado de www.redalyc.org/articulo.oa?id=64039200004 